\title{
Reduction of energy consumption and damage of tubers when digging potatoes
}

\author{
S.A. Shishlov*, N.A. Chugaeva, and A.N. Shishlov \\ Primorskaya State Academy of Agriculture, Ussuriisk, Primorye region, Russia
}

\begin{abstract}
The analysis of potato production in Primorsky Krai of the Russian Federation is given over the last five years. The practice of using existing digging working bodies of potato harvesters on heavy soils of Primorsky Krai showed that the digging process is energy-consuming and does not meet agrotechnical requirements for tubers' damage. Long-term research and analysis of literary sources have shown that the greatest energy costs and significant tubers' damage occur at the stage of share entering the soil and moving tuberiferous mass on the elevator. On the basis of the existing designs' analysis of potato harvesters' digging working bodies and conducted patent search, the original design of finger type share is proposed. The proposed design allows to reduce the unit's draught resistance and reduce the amount of soil entering the elevator. Installation of the proposed working body will reduce energy costs, reduce tubers' damage and improve the quality of soil cleaning from tubers' surface . Based on the study results, patents for useful models confirming the technical novelty of the proposed design were obtained.
\end{abstract}

\section{Introduction}

Potatoes are one of the main crops cultivated in Primorsky Krai; more than $90 \%$ of the potatoes produced in the region is harvested on private farms, peasant farms and individual entrepreneurs. The main indicators of potato production for five years are shown in table [1].

Table 1. Main indicators of potato production in Primorsky Krai (in farms of all categories) [1].

\begin{tabular}{|c|c|c|c|c|c|}
\hline Date & 2015 & 2016 & 2017 & 2018 & 2019 \\
\hline $\begin{array}{c}\text { Indicator } \\
\begin{array}{c}\text { Area occupied by } \\
\text { potatoes, thousand } \\
\text { hectares }\end{array}\end{array}$ & 21.7 & 20.1 & 20.1 & 20.3 & 18.8 \\
\hline $\begin{array}{c}\text { Gross harvest of potatoes, } \\
\text { thousand tons }\end{array}$ & 239.8 & 216.9 & 240.0 & 235.1 & 198.7 \\
\hline Potato yield, cwt/ha & 116.2 & 119.3 & 125.8 & 130.9 & 113.7 \\
\hline
\end{tabular}

The main indicators presented in Table 1 show that during the last five years the area occupied for potato cultivation has been decreasing: in 2019 it was $86.6 \%$, in relation to the

\footnotetext{
* Corresponding author: shishlov-meh@mail.ru
} 
same indicator of 2015 the decrease amounted to $13.4 \%$. Due to increased yields, gross harvest in 2015 - 2018 slightly changed. In 2019, due to a sharp decline in yields and a reduction in acreage, there was a decrease in gross yield. The average yield for the past five years is $121.2 \mathrm{cwt} / \mathrm{ha}$, with the yield of more than $300 \mathrm{cwt} /$ ha planned by breeders for potato varieties zoned for Primorye.

Analyzing the yield indicators, we can conclude that the potential embedded in zoned potato varieties is not fully used. In addition to adverse soil and climatic conditions, the reasons for this may be the following: poor-quality seed stock, non-compliance with cultivation agrotechnics, tubers loss as a result of incomplete digging and others. Theoretical analysis and operational practice of devices for separating tubers from soil lumps in potato harvesters show that there is yet no effective way of separating impurities and mainly soil lumps from potato tubers without damage [2-7]. Therefore, the problem of finding digging working bodies has not lost its importance, and the question of creating and researching new more effective digging working bodies of potato harvesters is relevant. Purpose of research improving the efficiency of potato digging process by reducing energy costs due to improving the design parameters of potato digging working bodies.

\section{Materials and methods}

The common methodological basis of the research was the application of a complex and systemic approach that provides a comprehensive review of the potato digging process considering the real relationship of systemically important parameters. Methods and laws of applied mechanics, mathematics, physics were used in theoretical research.

Preliminary laboratory studies were performed by the modeling method on the soil box using an experimental installation. The design of the experimental installation made it possible to mount any share, change movement speed, depth magnitude and inclination angle of the share. The shares' installation angle changed stepwise within: 17, 19, 21, 23, 25,27 degrees.

The installation movement speed was regulated by the gear ratio of the drive in the range of $1.5-3.6 \mathrm{~km} / \mathrm{h}$. The installation was driven by a $10 \mathrm{~kW}$ electric motor A 02-61-6. To measure the travel, a track measurement wheel associated with a contact speed sensor with 11 pairs of contacts to improve measurement accuracy was installed: one-wheel turn forms 11 pulses, each equal to a path of $0.04 \mathrm{~m}$.

The traction at installation moving was fixed by a calibrated tensometric element.

Field experimental studies were carried out in the conditions of agricultural machinery's operation in fields with a slope of 3-5 degrees and $14-19 \%$ soil moisture.

Determination of soil hardness change by ridge depth was carried out using Revyakin hardness tester with preliminary calibration of the device's spring, the diameter of the tip was taken as $0.012 \mathrm{~m}$. At the site of ridge soil hardness determination, the tip was smoothly immersed to a depth of $250 \mathrm{~mm}$ and a change in soil hardness was simultaneously recorded every $50 \mathrm{~mm}$ in depth.

The hardness value was calculated by the formula: $\mathrm{p}=\sum \frac{h k}{n S}$, where:

$h$ - depth of tip immersion into the ridge;

$k$ - rigidity of the hardness tester spring;

$n$ - number of measurements;

$S$ - the tip cross-section area.

The research results' processing was performed by the mathematical statistics method using the "STATISTICA" program.

Exploration of geometric shape and share parameters was based on patent search. The design of share's geometric parameters was based on the minimum effort hypothesis of soil 
introduction with full row digging and partial separation of the soil during the layer movement on the share without tubers' damage. As a result, two patents for utility models $[8,9]$ were obtained. Experimental shares were produced according to the calculated parameters, which were mounted on the KTN-2B potato digger in the assembly with the MTZ-82 tractor, the tests were carried out in the field. During the research, general methods were used with the development of private methods for evaluating the work of the studied units. Load parameters records were based on the strain-gaging method. The energy costs value was calculated according to the PTM method [10].

\section{Results and discussion}

Three types of shares were used in laboratory and field studies: basic, finger and experimental (Figure 1-3). The basic share (Fig. 1) is made as a solid wedge-shaped plate with tapered sides having a sharpening angle to reduce the resistance force to the cutting of undermined tuberiferous layer. Extension cords are swiveled on the back side of the share allowing for partial soil separation between them. The main disadvantages of the basic share are uneven layer digging in width and depth and transportation of the entire mass of the excavated soil to the working surface of the share. The design of the basic share leads to partial tubers' cutting due to their uneven location along the depth and width of the ridge and an increase in energy costs for moving the digging mass.

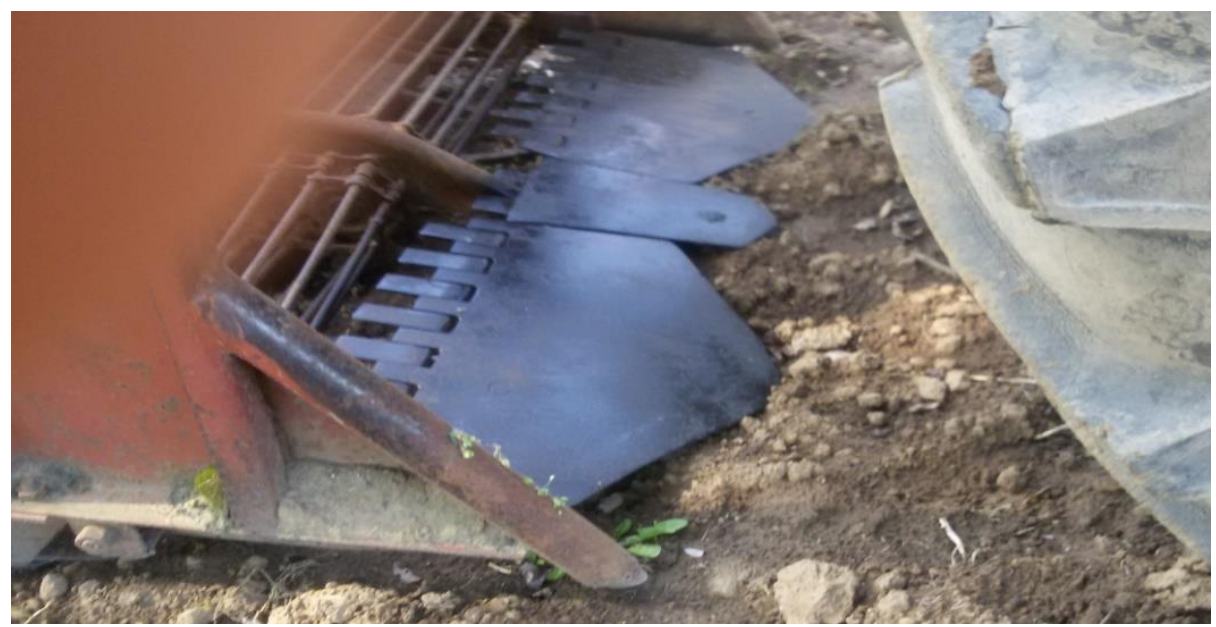

Fig. 1. Potato digger with basic shares.

Finger share (Figure 2) partially eliminates the shortcomings of the basic one by separating digged soil between the fingers, but still causes tubers' cutting since the fingers have different length. The rounded nose surface of the finger creates additional resistance to its introduction into the soil and inter-finger space clogging with the remains of weeds and potato foliage [9]. 


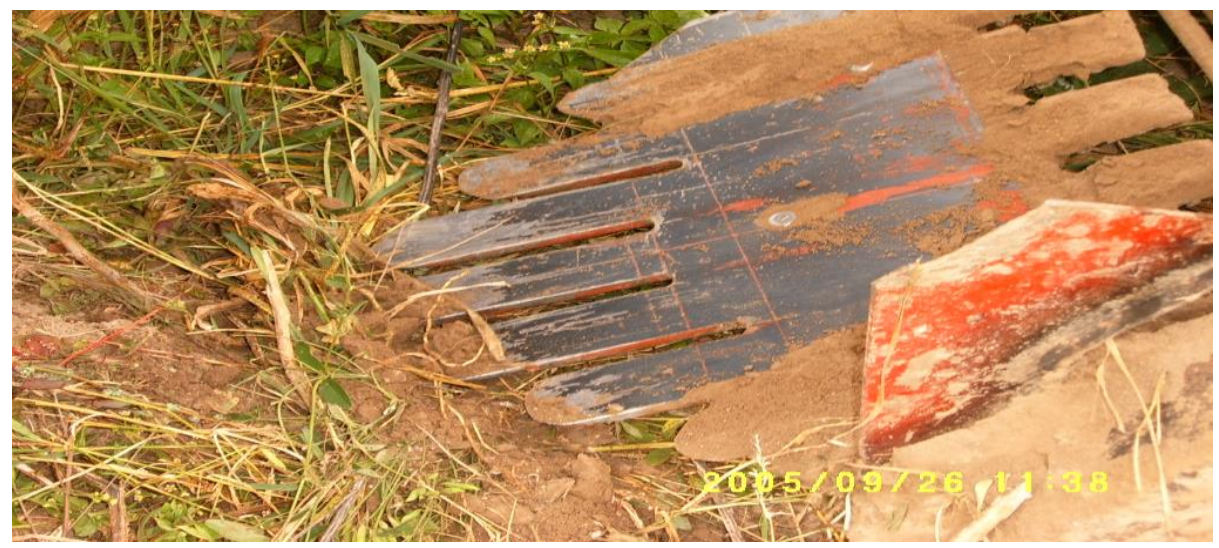

Fig. 2. Potato digger with finger shares.

To eliminate the shortcomings of the basic and finger shares, the experimental share (Figure 3) has a rectangular shape with fingers of the same length and a trapezoid crosssection shape [10].

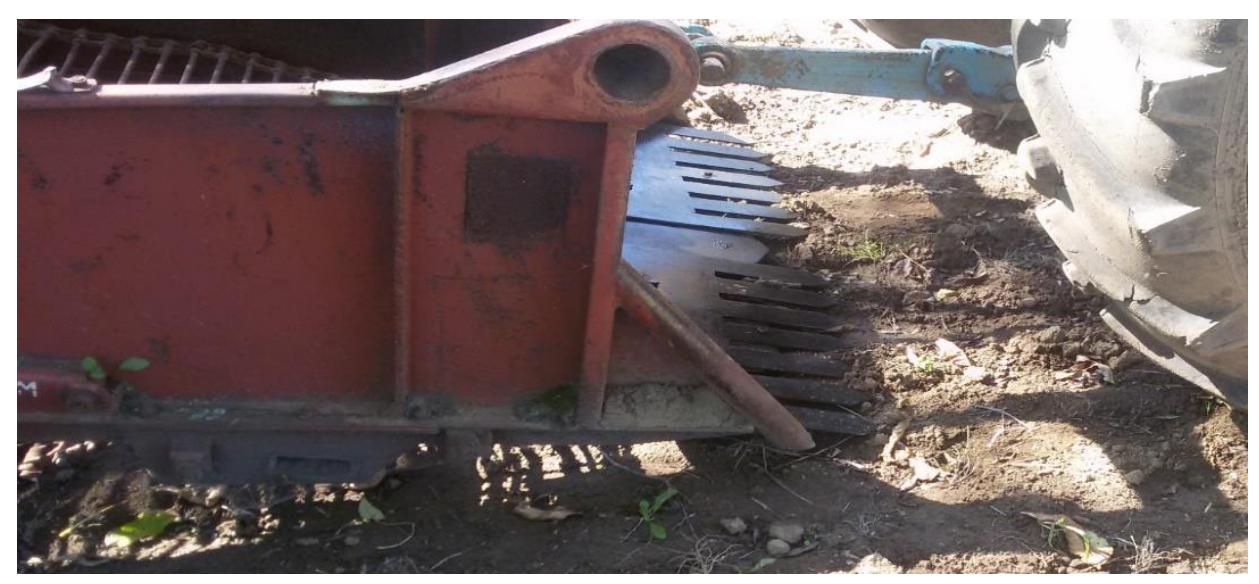

Fig. 3. Potato digger with experimental shares.

As a result of laboratory tests on the soil box, it was established that for the studied shares' types, the digging process with a steady share's movement occurs at its inclination angle of 23-26 degrees to the plane of motion. At angles smaller than 23 degrees, the share "pops up" due to resistance to its introduction by a denser lower soil layer; at angles over 26 degrees, the soil piles up on the share surface, the strongest pileup is noted on the basic (Fig. 1) and finger share (Figure 2), insignificant - on the experimental share (Figure 3). The resistance force to movement of the basic share at an angle of 23 degrees amounted to $2760 \mathrm{~N}$, finger $-2370 \mathrm{~N}$, experimental $-2150 \mathrm{~N}$, which indicates a decrease in energy costs during digging when using experimental share.

To determine the force of share introduction into the soil, experiments were carried out in the field and the regularity of soil hardness change in the height of the digged ridge was established. The obtained results suggest that soil hardness on the ridge increases from its top to the base. (Fig. 4). 


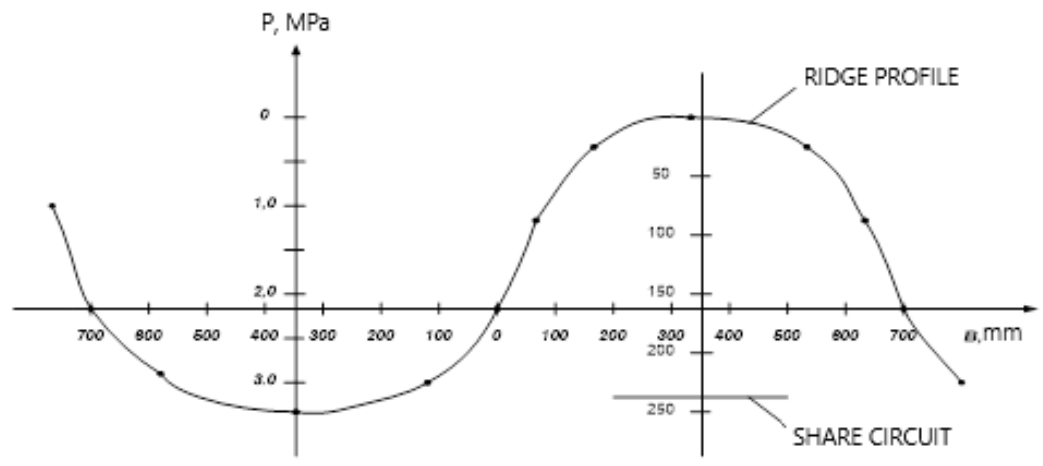

Fig. 4. Soil hardness change by ridge height.

At the ridge depth from 0 to $100 \mathrm{~mm}$, the soil hardness varies from 0.5 to $1.0 \mathrm{MPa}$; at a depth of 100 to $200 \mathrm{~mm}$ it increases by 2 times and is within $2.0-2.2 \mathrm{MPa}$, directly at subplough layer $(250 \mathrm{~mm})-2.4-2.7 \mathrm{MPa}$ (Fig. 4). This pattern of soil hardness change by ridge depth indicates that the most loaded is the front part of the digging body, which raises overlying soil layers on itself while cutting the ridge at the base. The unevenness of digging body load along the length contributes to the formation of the pressure bulb on its surface, causing additional force to move the share. This confirms our hypothesis that in order to reduce the effort of share introduction into the soil, it is necessary that the cutting area and the digging layer movement area along the share are minimal. Consequently, replacing the basic continuous share with a finger one, we will get a reduction in the effort to move the share by $15-16 \%$ and a decrease in tubers' damage from $0.5 \%$ for the basic to $0.4 \%$ for the finger.

The inclined cutting part of the basic share and the different fingers' length of the finger share lead to trimming the unevenly spaced tubers in the depth and width of the ridge. In order to ensure even ridge digging in depth, an experimental share was installed on the potato digger, having the same length of the fingers sharpened at a 30 degrees angle at the end. The fingers' side surfaces are also sharpened at 30 degrees along the length to reduce the friction force when moving the undercut layer. Tests have shown that experimental share reduces displacement force by $18-20 \%$ compared to the basic one, potato tubers damage does not exceed $0.2 \%$. Due to the same finger length, the soil between them is evenly pushed along the length without causing the pressure bulb formation on the share surface; as a result, less soil enters the share surface and the elevator due to pre-separation on the fingers. Tubers are better cleaned and less damaged.

\section{Conclusions}

1. Experimental digging share has better self-cleaning and allows to reduce tractive resistance by $18-20 \%$.

2. With an increase in the unit movement speed with an experimental digging lump by 0.06 $\mathrm{m} / \mathrm{s}$, the productivity increases by $0.10 \mathrm{ha} / \mathrm{h}$, tubers' damage does not exceed $0.2 \%$.

3 . When using a potato digger with experimental digging share, direct operating costs are reduced by $21 \%$, fuel costs - by $3.2 \%$, which reduces the total energy consumption by $669.85 \mathrm{MJ} / \mathrm{ha}$ in comparison to the basic share. 


\section{References}

1. Primorye in numbers: Summary statistical collection, 66 (2020)

2. S.S. Tubolev, S.I. Shelomentsev, K.A. Pshechenkov, V.N. Zeyruk, Machine technologies and machinery for potato production, 316 (2010)

3. S.N. Borychev, Machine technologies for potato harvesting using advanced diggers, loading diggers and harvesters, 40 (2008)

4. G. Theiben, Profi, 6, 22 (1993)

5. V.N. Sokolov, Improvement of the technological process of potato harvesting, 23 (2001)

6. N.V. Kuzmin, Methods of reducing the damage of potato tubers and improving potato harvesting machines, 40 (2005)

7. M.Yu. Kostenko, Potato harvesting technology in difficult field conditions with the use of innovative solutions in the design and maintenance of harvesters, 40 (2011)

8. N.V. Byshov, S.N. Borychev, Y.N. Abramov, M.B. Uglanov, M.Y. Kostenko, Bioscience Biotechnology Research Communications, 12 S5, 312 ( 2019)

9. A.V. Usatov, A.N. Shishlov, Patent 43430 RF A01D 17/00 (2000.01), Potato harvesting machine digging body, (2005)

10. A.N. Sergeev, S.A. Shishlov, A.N. Shishlov, M.S. Shapar', Patent 176092 RF A01D 13/00 (2006.01), The digging body of the potato harvesting machine (2017)

11. V.P. Elizarov, V.A. Kolos, Yu.N. Sapyan, D.A. Maksysov, Yu.L. Morozov, A.Yu. Izmailov, Methods of fuel and energy assessment of crop production, 84 (2012) 